\title{
REGULAÇÃO ESTATAL E DESAFIOS DA EXPANSÃO MERCANTIL DA EDUCAÇÃO SUPERIOR*
}

\author{
VALDEMAR SGUISSARDI ${ }^{* *}$
}

\begin{abstract}
RESUMO: Tendo como pano de fundo a tramitação no Congresso Nacional de um projeto do Executivo que propõe a criação do Instituto Nacional de Supervisão e Avaliação da Educação Superior (Insaes), este artigo questiona, antes de tudo, o caráter público da regulação estatal, que se faz na educação superior, em geral, em detrimento da efetiva avaliação institucional. Mostra, em seguida, a acelerada e questionável mercantilização desse nível de educação, enfatizando, em especial, os desafios que tal fato representa para a regulação estatal de caráter público. Para responder às principais questões formuladas na problematização do tema, este artigo examina conceitos tais como os de estatal, público, privado, privado/mercantil, regulação, agências reguladoras e o de regulação, dita supervisão e avaliação, da educação superior.
\end{abstract}

Palavras-chave: Regulação. Regulação estatal. Regulação da educação superior. Mercantilização da educação superior.

\section{STATE REgUlation AND THE CHALLENGES OF THE GROWTH OF HIGHER EDUCATION MERCANTILIZATION}

\begin{abstract}
Considering the introduction of a bill in the National Congress which proposes the creation of Insaes - National Institute for Higher Education Supervision and Evaluation -, this article questions, first of all, the public character of State regulation regarding higher education in general, to the detriment of the actual institutional evaluation. Then, it shows the fast-growing and arguable mercantilization of such level of education, especially emphasizing the challenges imposed by such fact on the public State regulation. In order to answer the main questions raised during the problematization of the theme, this article will examine concepts such as state, public, private, private/mercantile, regulation, regulating offices, and higher education regulation, or supervision and evaluation.
\end{abstract}

Key words: Regulation. State regulation. Higher education regulation. Higher education mercantilization.

\footnotetext{
* Texto apresentado no IV Seminário de Educação Brasileira (SEB/Cedes), Campinas (SP), de 20 a 22 de fevereiro de 2013.

** Faculdade de Educação da Universidade Federal de São Carlos (Ufscar). São Carlos (SP) - Brasil. (Professor titular aposentado).

Contato com o autor: <vs@merconet.com.br>
} 


\section{Regulation de L'ETAT ET DEFIS DE L'EXPANSION MARCHANDE DE L'ENSEIGNEMENT SUPERIEUR}

RÉSUMÉ: En ayant le projet de création de l'Insaes - Institut National de Surveillance et d'Evaluation de l'enseignement supérieur - proposé par l'Exécutif au Congrès National, cet article, tout d'abord, pose des questions sur le caractère public de la régulation de l'État, celle qui, dans l'enseignement supérieur, est faite en général au détriment de l'évaluation institutionnelle. Il montre ensuite la marchandisation accélérée et discutable de ce niveau d'éducation, soulignant en particulier les défis que ce fait signifie à la régulation de l'État de caractère public. Pour répondre aux principales questions formulées dans l'introduction du thème, cet article examine les concepts tels que ceux de l'Etat, bien que le public/privé, "privé/marchand", l'agence de régulation, et celui de régulation, dite surveillance et évaluation de l'enseignement supérieur.

Mots-clés: Régulation. Régulation de l'État. Régulation de l'enseignement supérieur. Marchandisation de l'enseignement supérieur.

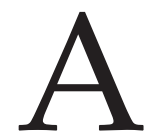

tramitação no Congresso Nacional do Projeto de Lei (PL) n. 4.372/12, do Poder Executivo, que, se aprovado, criaria o Instituto Nacional de Supervisão e Avaliação da Educação Superior (Insaes), sugere algumas oportunas questões sobre o significado dessa eventual nova Lei. Entre essas, uma das mais, senão a mais intrigante é: como se dará parte importante da regulação estatal da educação superior - que é disto que se ocuparia o Insaes - diante da crescente expansão mercantil e da visível tendência à oligopolização desse nível de educação e formação profissional? Sob a tutela do aparelho estatal - em que tenderiam a prevalecer os interesses do polo privado/mercantil - seria viável uma efetiva regulação de interesse público desse nível de educação, em cuja ampla maioria de suas instituições impõe-se a valorização dos capitais nelas investidos? O Insaes, no seu formato previsto, reuniria as melhores condições para tanto?

Para responder, ainda que por hipótese inicial, a essas questões, será necessário examinar alguns conceitos, realidades e funções que conformam as relações do Estado atual e suas instituições públicas, privadas ou particulares. Entre esses, os conceitos de estatal, de público, de privado e de privado/mercantil, além de considerar e problematizar a função social da educação superior e sua mercantilização e oligopolização, assim como a regulação estatal, as agências reguladoras e a regulação, dita supervisão e avaliação, da educação superior.

Caberá também questionar a formação de profissionais para essa eminente função de regulação estatal, tendo em vista, principalmente, uma genuína regulação de interesse público do sistema federal de ensino. Sabe-se que, atualmente, o Instituto Nacional de Estudos e Pesquisas Educacionais Anísio Teixeira (Inep) e, em seu âmbito, o Sistema Nacional de Avaliação da Educação Superior (Sinaes) não possuem 
um corpo permanente de avaliadores especialistas e que, de igual modo, a quase totalidade das mais de 20 mil avaliações in loco de cursos de graduação do último decênio foi realizada por não especialistas. Além do que, os próprios fundamentos teórico-metodológicos desse sistema de avaliação têm sido objeto de consistentes críticas, em especial a partir das mudanças nele operadas em 2007/2008.

\section{Aportes sumários sobre a regulação em geral}

Embora nem no nome, nem no corpo do Projeto de Lei utilizem-se o verbo regular e o substantivo regulação, é disto, em última instância, que se trata. O Insaes substituirá, ampliando-lhe as funções, a recém-criada Secretaria de Regulação e Supervisão da Educação Superior (Seres) do MEC e seu presidente será também presidente da atual Comissão Nacional de Avaliação da Educação Superior (Conaes). Dos seus 550 cargos previstos no Projeto de Lei, 350 serão de especialistas em avaliação e supervisão da educação superior; 150, de analistas administrativos; e 50, de técnicoadministrativos.

Mais uma vez parece tentar-se oficialmente burlar a realidade. Há muitos anos convive-se no Brasil com claros mecanismos estatais de regulação e controle da educação superior, divulgados, acolhidos e enaltecidos sob nomes suposta e socialmente mais aceitáveis, como Sistema de Avaliação da Pós-Graduação da Capes ${ }^{1}$ e Sistema Nacional de Avaliação da Educação Superior.

A regulação é um fenômeno coessencial ao Estado moderno, seja em seu aparelho restrito, seja em seu âmbito ampliado da sociedade em geral e do mercado econômico em particular. A regulação econômica dá-se concomitante e, muitas vezes, confundindo-se com a atividade regulatória a cargo do aparelho do Estado. Sobre sua razão de ser, Cabral Neto (2012, p. 19) escreve: "Historicamente, a regulação econômica é considerada como necessária para ordenar as relações de mercado, com vistas a corrigir as falhas próprias desse mecanismo e prevenir a possibilidade de uma situação de desordem que provoque uma crise de efeitos duradouros".

Segundo Avritzer (apud CABRAL NETO, op. cit.), a regulação econômica adquire variadas formas "de acordo com os contextos em que se desenvolvem e ganham materialidade". São muitas as formas de regulação e, em especial, de duas naturezas: técnica (União Postal Universal) e política (Banco Mundial, FMI e ONU).

Esses conhecidos organismos multilaterais exercem seu poder em todo o planeta e impõem-se, mais ou menos, de acordo com a força de resistência de cada um dos países envolvidos. Os países do centro do capitalismo, como os EUA e outros, não apenas lhes resistem, como se autorregulam e fortalecem o poder de fogo desses organismos sobre os países da periferia e semiperiferia, fragilizados e dependentes. 
A regulação dá-se em vários níveis - transnacional, nacional e local - e sob várias modalidades de atividade regulatória. No caso da economia: 1) a que cuida da propriedade pública de firmas ou setores inteiros da economia; 2) a que se ocupa da propriedade privada pela via de órgãos reguladores do Estado; 3) as várias formas de autorregulação por meio de arranjos corporativos; 4) e "a regulação pública com regime de propriedade privada, tipicamente americana, baseada em uma forma institucional peculiar: a agência regulatória dotada de graus crescentes de autonomia" (idem, ibid., p. 21).

Compõem o primeiro nível, além dos anteriormente citados, o Banco Interamericano de Desenvolvimento (BID), a Organização Mundial do Comércio (OMC), a União Europeia (UE) e o Mercado Comum do Sul (Mercosul), entre outros.

O segundo nível, nacional, é constituído desses diferentes tipos de atividades regulatórias ou de combinações deles. A partir do processo de tardia adesão do Brasil, nos anos de 1990, ao ajuste neoliberal e ao modo de produção de acumulação flexível, em tempos de mundialização do capital de predominância financeira e com intensificação do Investimento Externo Direto (IED), adota-se aqui, em especial, a quarta dessas modalidades de atividade regulatória, isto é, o mecanismo das agências reguladoras (AR).

A vantagem desse modelo - AR -, afirma Souto, seria "a substituição do controle político e burocrático pelo controle técnico, assegurado pela escolha de seus membros calcada no mérito e submetida à aprovação parlamentar, com direito a mandato fixo" (apud CABRAL NETO, op. cit., p. 21-22). Alerta Souto, entretanto, que "A agência não é um órgão de defesa do consumidor, mas uma entidade que busca o equilíbrio entre os interesses nos setores regulados (mercado específico), devendo ficar equidistante de consumidores, fornecedores e do poder público" (ibid.).

Isso ocorre, evidentemente, no plano ideal, porque, como se verá adiante, nem o Estado e nem as AR são uma realidade neutra a pairar acima dos interesses privados e particulares de classe, e interesses públicos ou privado/mercantis. No plano ideal, as AR visariam garantir que os provedores públicos ou privados forneçam os bens e serviços necessários aos consumidores e usuários com o máximo de equidade. Sobre a finalidade das AR, Nunes, Ribeiro e Peixoto (2007, p. 4) acrescentam:

Do ponto de vista teórico, agências são instituídas para combater falhas de mercado, tais como assegurar a competitividade de setores da economia, diminuir custos de transação inerentes à provisão de bens públicos, reduzir assimetrias de informação entre agentes econômicos, combater externalidades negativas advindas das interações econômicas, universalizar serviços e promover interesses dos consumidores [...].

As AR cumprem funções típicas do Poder Executivo - concessão e fiscalização de atividades e direitos econômicos -, do Poder Legislativo - edição de normas, regras 
e procedimentos com força legal - e do Poder Judiciário - julgamento e imposição de penalidades, interpretação de contratos e obrigações entre agentes econômicos.

\begin{abstract}
Assim, as agências produzem regras e normas que imputam custos às unidades reguladas, atraindo, complementando ou contrariando interesses privados e públicos. Isso ocasiona uma inevitável interação entre reguladores e regulados, com recorrentes possibilidades de captura do órgão regulador por parte de agentes econômicos para subverter os princípios do mercado a favor de interesses específicos. (Idem, ibid.)
\end{abstract}

A propósito dessa captura, os autores enfatizam que "Não existe, portanto, regulação neutra, nem regulação inocente" e que "Muitos regulados buscarão normas regulatórias para protegê-los da competição, diminuir seus custos de transação, criar barreiras de entradas em seu setor de atuação, protegê-los de demandas do público, etc.". Sua conclusão é um alerta para a ingenuidade de alguns e a esperteza de outros:

\footnotetext{
Nem toda regulação, portanto, é a favor do interesse público ou da promoção do mercado competitivo. O aparato regulatório, criado para sanar imperfeições do mercado, pode tornar-se, ele mesmo, uma espécie de mercado onde regulação é "comprada" e "vendida". O mercado regulatório pode se constituir, assim, em um selvagem campo de lutas de interesses e tanto pode estar voltado para o público quanto para a preservação de privilégios. Daí a pertinência das recorrentes discussões sobre independência, controle e accountability das agências reguladoras. (NUNES; RIBEIRO; PEIXOTO, op. cit., p. 5)
}

As primeiras AR no Brasil foram criadas no contexto da Reforma do Estado iniciada em 1995. E o foram para serem órgãos independentes da administração direta em três setores da economia, objetos de privatização e/ou quebra de monopólios estatais: Agência Nacional de Energia Elétrica (Aneel), Agência Nacional de Telecomunicações (Anatel) e Agência Nacional do Petróleo (ANP). Entretanto, a experiência das AR foi vista por especialistas e agentes econômicos, em geral, como pouco exitosa, "justamente por não atuarem sob um adequado marco regulatório, impossibilitando-as de se constituir em verdadeiros órgãos de Estado" (idem, ibid.).

\title{
Da regulação em geral à regulação da educação superior
}

Embora não inseridas em órgãos nomeados como AR, as funções de regulação e controle dos "serviços educacionais", em especial os de nível superior (graduação e pós-graduação), são objeto de atividades regulatórias há mais de um século em alguns países, como os EUA e países europeus (STUBRIN, 2005). No Brasil, desde, ao menos, o Estatuto das Universidades (1931) e o primeiro Conselho Nacional de Educação (Decreto n. 19.850/31), passando pelo Conselho Federal de Educação (Lei n. 4.024/61), até o atual Conselho Nacional de Educação (Lei n. 9.131/95), a regulação 
e o controle do sistema federal de ensino se fazem presentes pela via dos conselhos e instâncias burocráticas do Ministério da Educação ou similares.

Como atividade de avaliação institucional, com traços de uma experiência de avaliação educativa que as posteriores, muito mais próximas da regulação e controle, em geral, não terão, registre-se a experiência do Programa de Avaliação Institucional das Universidades Brasileiras (Paiub), de 1993. ${ }^{2}$ Esse Programa, cuja experiência tem sido avaliada por especialistas como muito rica e promissora, foi rapidamente ignorado e esvaziado de recursos logo no primeiro mandato do Presidente F. H. Cardoso (1995-1998).

Com base nas Leis n. 9.131/95 e 9.394/96 (LDB), esse Programa foi substituído, a partir de 1997, pelo Exame Nacional de Cursos (ENC) e por outros mecanismos de regulação como a Análise de Condições de Ensino (ACE) e a Avaliação das Condições de Oferta (ACO). Nesse mesmo ano implantava-se o atual Sistema de Avaliação da Pós-Graduação, conhecido como Modelo Capes de Avaliação (SGUISSARDI, 2009). Aqueles, sob os cuidados do Inep, e este, sob os da Capes.

Belmiro Cabrito assim explicita o que entende por regulação das políticas e "serviços" educacionais:

Em termos amplos, e no quadro institucional, entendo por regulação o modo como os portadores de autoridade coordenam, controlam e influenciam o sistema educativo e seus atores, por meio de regras, normas, pressões e constrangimentos, condicionando a ação daqueles atores em função dos objetivos políticos que perseguem. Neste sentido, a regulação concretiza-se nas ações que os detentores dos órgãos de poder, isto é, aqueles que possuem a capacidade para exercer constrangimentos com êxito e dentro da legalidade, realizam com o objetivo de levar os governados a executarem suas decisões. (CABRITO, 2011, p. 187)

Como em relação à economia, no campo educacional - este cada vez mais um verdadeiro mercado -, a regulação pode ser de vários âmbitos e dimensões: transnacional, nacional e local. No primeiro caso, são amplamente conhecidos os constrangimentos sofridos, pelos países da América Latina, Caribe, África e Ásia, diante de programas e "recomendações" do Banco Mundial (BM). Houve anos, mormente no final dos anos de 1990, em que o Banco Mundial frequentou a grande mídia nacional quase com tanta assiduidade quanto o Banco Central, o BNDES e o FMI, tamanho era seu envolvimento nas políticas públicas em geral e na educação em particular em nosso país ${ }^{3}$ (SGUISSARDI, 2000). “Ele [o BM] está presente por todas as regiões, em especial aquelas que nem sempre possuem capacidade econômica e política para lhe dizer não" (CABRITO, op. cit., p. 188).

Cabrito (op. cit., p. 190) refere-se à UE como sendo hoje a principal instância reguladora transnacional do ensino superior na Europa, definindo normas e diretivas 
que se impõem com força de lei, corporificando "a tendência para a liberalização deste serviço público nos Estados-membros em geral".

Dentre as principais medidas regulatórias implementadas pela UE no campo educacional, o autor destaca:

[...] a diversificação de mecanismos de controle; o reforço da regulação pelo mercado; a intensificação da avaliação externa das instituições e dos docentes; a erosão da profissionalidade docente e do poder dos sindicatos; a desresponsabilização financeira dos Estados; a abertura do ensino superior à iniciativa privada; a promoção da concorrência por meio dos quase-mercados; ou a abertura da universidade pública à sociedade civil, nomeadamente através de conselhos gerais, conselhos de curadores, etc., que representam as "forças vivas da sociedade civil" (o mesmo é dizer, neste caso, o mundo empresarial). (ibid.)

Finalmente, cabe referir, entre essas medidas regulatórias da UE no campo da educação superior, o Processo de Bolonha que, além de regular a educação superior europeia, tenderia a interferir nos sistemas de ensino superior de outros continentes em busca de "mercado educacional", conforme estudo de Denise Leite e Maria E. H. Genro (2012)

\section{Contexto do acirramento dos processos regulatórios na educação superior}

A criação do Insaes talvez se constitua em importante primeiro passo para a unificação do processo de regulação da educação superior no Brasil, que ainda se vê dividido por diversos órgãos (CNE, Sesu, ${ }^{4}$ Inep, Capes) e, em especial, cindido entre graduação e pós-graduação, embora o ranking das Instituições de Educação Superior (IES), composto a partir dos "índices" divulgados pelo Inep, já considere os escores dos programas de pós-graduação stricto sensu de alçada da Capes.

No caso da regulação dos níveis de graduação e pós-graduação, esse passo coroaria uma caminhada de pelo menos 15 anos que se inicia com o abandono oficial do Paiub e com a adoção do ENC/Provão e do Modelo Capes de Avaliação nos anos de 1997/1998. Isto, não por acaso, em contexto muito bem demarcado da economia mundial e nacional, de clara adesão ideológica e política voluntária dos dirigentes e do empresariado do país a teses ultraliberais e receituários político-econômicos, como o do Consenso de Washington (FMI, BM, BID, OMC e outros) e seu catálogo de recomendações ou imposições liberalizantes.

Entre as medidas recomendadas e então adotadas, estão: a) equilíbrio orçamentário com redução de gastos públicos no setor de serviços sociais, abertura comercial e liberalização financeira; b) Reforma Gerencial do Aparelho do Estado, com 
adoção de conceitos como atividades não exclusivas do Estado e competitivas (entre estas a educação), propriedade pública não estatal e organização social; c) combate ao atual modelo universitário, supostamente seguidor do modelo humboldtiano de universidade, que associaria ensino e pesquisa (e extensão), e a adoção de diretrizes e propostas que conduziriam à máxima diferenciação institucional e a uma distinção, defendida por documentos do Banco Mundial (WORLD BANK, 1994), entre universidades de pesquisa (centros de excelência) e universidades de ensino; d) aprovação de leis e normas que apontassem na direção, seja da liberalização/flexibilização das IES, seja na adoção de um conceito de autonomia que significasse autonomia financeira e não de gestão financeira, isto é, o afastamento do Estado da manutenção exclusiva e prioritária das IES oficiais (preceito constitucional), restando-lhes o apelo a recursos financeiros complementares junto à iniciativa privada.

Foi nesse contexto que o Brasil rapidamente assumiu seu posto de coliderança dos países emergentes e de parceiro coadjuvante dos países detentores da hegemonia na mundialização do capital com predominância financeira. Em poucos anos, o investimento externo direto, com ou sem fins especulativos, atingiu recordes sobre recordes (CHESNAIS, 1996). O país viu seu parque industrial deteriorar-se e ser dominado por empresas transnacionais que hoje detêm o monopólio de muitos setores fundamentais da economia, enquanto retoma seu papel em geral subalterno de exportador de matérias-primas oriundas do subsolo ou do agronegócio, com baixo ou nenhum valor agregado.

Faz parte essencial desse contexto a transformação do papel da ciência e da tecnologia para o aumento da produtividade, competitividade e rentabilidade da indústria e dos serviços. Disto deriva sua exponencial valorização como mercadoria, assim como se valorizam as instituições com potencial de produzi-las, isto é, as universidades e os institutos de pesquisa. Cada vez mais se verifica, na economia atual, maior predominância dos bens imateriais sobre os materiais e a universidade passa a ser vista como essa nova empresa produtora, ainda que indireta, de mais valor. Universidade como organização mensurável ou genuína empresa econômica que precisa comprovar sua eficiência e eficácia no mercado. Disso decorrem, em grande medida, os rankings universitários, que privilegiam especialmente as ditas universidades de classe mundial, sediadas em dois ou três países anglo-saxônicos e emuladas pelas universidades dos países periféricos.

Os processos de certificação em massa (na graduação) e de alta qualificação (na pós-graduação stricto sensu) seriam alcançados ao custo de maior intensificação e precarização do trabalho docente das Ifes, aproximando-se suas condições de trabalho das dos docentes das cerca de 2.000 IES privado/mercantis, comprovadamente muito piores que as dos trabalhadores em geral, portadores de iguais níveis de qualificação profissional. 
A identificação da ciência e da tecnologia (e inovação) como elementos importantes de valorização do capital, assim como o concurso vital do fundo público nas atividades de produção científico/tecnológica, que as empresas transnacionais e nacionais dificilmente patrocinariam, está na origem das profundas mudanças ocorridas na orientação das políticas de pesquisa de agências como o CNPq e a Finep. Se até o início dos anos 2000 predominava o financiamento pelo CNPq de projetos de demanda espontânea ou de balcão, em que os pesquisadores tinham quase total liberdade de escolha de temas e orientação, a partir dessa data verifica-se que cerca de dois terços dos projetos têm suas temáticas direcionadas por editais, ficando os pesquisadores, em sua maioria, sem liberdade de pesquisa (KATO, 2013).

Essa nova orientação do $\mathrm{CNPq}$, aliada ao cunho quantitativista do Modelo Capes de Avaliação, está na origem, como já bastante demonstrado, do fenômeno conhecido como produtivismo acadêmico (SGUISSARDI; SILVA JR., 2009) que hoje impregna não apenas as atividades dos professores e alunos da pós-graduação, mas estaria também "contaminando" a Iniciação Científica no nível da graduação (SANTOS, 2013).

Sinalize-se que foi exatamente no ano de 1997 que, pelo Decreto n. 2.306/97, a propósito da regulamentação da recém-aprovada Lei n. 9.394/96 (LDB), estabeleceu-se legalmente a liberação da propriedade e gestão das instituições de educação superior para mantenedoras ou empresas com fins lucrativos. A Constituição Federal já previa a oferta de serviços educacionais pela iniciativa privada, sem mencionar, entretanto, seu eventual caráter privado/mercantil.

É nesse contexto, portanto, que se acirra o processo regulatório e de controle sobre a educação superior, traduzido, no âmbito da graduação, pelo ENC/Provão, substituído em 2003 pelo Sinaes que, originalmente, lhe fazia oposição de princípios e de práticas, mas que, a partir de 2007/2008, sofreria importantes mudanças que o teriam reaproximado dos princípios e práticas típicos do ENC/Provão.

\section{O Insaes na esteira do Sinaes: a difícil conciliação entre medidas de regulação e procedimentos de avaliação institucional}

A criação do Insaes tende a modificar o processo de supervisão e avaliação da educação superior. Modificar-se-iam, portanto, aspectos importantes do processo de regulação, alterando-se os papéis até então desempenhados por secretarias do MEC, como a Seres e a Sesu; pelo Inep e, em seu âmbito, pelo Sinaes e pela Conaes.

A questão que se põe refere-se à perspectiva de mudança que deverá sofrer o processo de regulação, normalmente denominado de avaliação e hoje representado 
pelo Sinaes, na sua configuração que remontaria não ao Sinaes original, de 2004, mas ao Sinaes de 2007/2008. Diversos especialistas e responsáveis pela proposta que deu origem ao Sinaes, instituído pela Lei n. 10.861/04, têm manifestado seu profundo desacordo com as mudanças introduzidas nesse Sistema Nacional de Avaliação a partir dos anos de 2007/2008. ${ }^{5}$

As mudanças efetuadas em 2007/2008 no Sinaes - introdução de índices como Conceito preliminar de cursos (CPC), Indicador de desempenho esperado e observado (IDD; este de 2005) e Índice geral de cursos (IGC); mudança de pesos atribuíveis a esses índices e desvalorização da avaliação institucional, em especial da autoavaliação - levaram o ex-presidente da Comissão Especial de Avaliação (CEA) a questionar se "O Sinaes se reduziu a índices?" e a afirmar, sem meias palavras: "As recentes ações do Inep interrompem a construção desse processo participativo e promovem o retorno a posturas, axiomas e enfoques próprios do paradigma técnicoburocrático" (DIAS SOBRINHO, 2008, p. 819).

A avaliação mais geral é de que se praticou verdadeiro retrocesso teórico e político a pretexto de se resolverem questões práticas, como a dos atrasos burocráticos relativos à autorização, reconhecimento e renovação de reconhecimento de cursos, e de credenciamento e recredenciamento de IES.

Cabe retomar aqui algumas reflexões, feitas quando dessas mudanças do Sinaes, que, tendo em conta diversas premissas, visavam explicar por que o Sinaes original teve seus dias contados e sua trajetória redirecionada.

No âmbito do aparelho de um Estado de natureza semipública ou semiprivada - como se caracteriza o Estado brasileiro -, as medidas de regulação e controle tendem a entrar em contradição com (e prevalecer sobre) os procedimentos de avaliação institucional e educativa. Estes se assentariam na autonomia da cultura de avaliação, que, como se sabe, não tem sido característica do sistema de educação do país, nem no setor público e, muito menos, no setor privado/mercantil (SGUISSARDI, 2008, p. 860).

Os obstáculos à conciliação entre regulação estatal e avaliação institucional decorreriam da própria natureza do Estado (se predominantemente público ou privado/mercantil); da concepção de educação superior (se um direito ou um serviço e bem privado/mercantil); do modelo de expansão da educação superior (se predominantemente pela via do estatal público ou do privado/mercantil); da natureza da regulação e do controle (se privilegia a formação do cidadão qualificado e crítico ou a competição, a eficiência e eficácia típicas do mercado); finalmente, da questionável conciliação entre regulação e controle estatais e avaliação que privilegie a cultura de avaliação e autoavaliação institucional (idem, ibid., p. 862). 


\section{O Estado regulador. 0 Estado privatizado. 0 estatal, o público, o pri- vado e o privado/mercantil}

Ao examinar os desafios que se põem para o Insaes, é oportuno discorrer sobre alguns conceitos ou noções que definem ou caracterizam o Estado brasileiro, responsável em última instância pelas atividades regulatórias nos setores econômicos e sociais.

Diante de novas políticas, novos programas, costuma-se fazer a distinção entre o que tem como âmbito de responsabilidade e ação o governo de turno ou o Estado: políticas de governo versus políticas de Estado. Em geral, estas ganham a preferência de analistas e militantes, porque, acredita-se, seriam isentas dos interesses partidários ou particularistas, neutras, de longo prazo, comprometidas com o interesse público, com a promoção da igualdade de oportunidades, mesmo que competitivas do mercado. Em outras palavras, com exceção dos que, antiestatistas convictos, creem na quimera da "mão invisível do mercado", tende a maioria dos cidadãos a identificar, no nível do senso comum, o estatal com o público, isto é, com os interesses coletivos da maioria.

No entanto, cabe questionar aqui essa identidade e as supostas virtudes do Estado regulador, mormente quando se trata da regulação e supervisão da prestação de "serviços educacionais".

A mundialização do capital de predominância financeira, a redução do Estado e do fundo público para os interesses sociais dos trabalhadores, dos de baixo, substituem o Estado-providência ou o Estado investidor/empresário pelo Estado regulador. Quanto a este, isto é, se houvesse dúvidas quanto a seu comprometimento com os de cima - no caso brasileiro, desde os tempos analisados por René Dreifuss, em seu clássico 1964: a conquista do Estado (1981) -, bastaria ouvir a voz de um exímio e respeitável analista dos tempos presentes, David Harvey, em seu recente livro O enigma do capital $e$ as crises do capitalismo: "Apenas agora em que o Estado entra em cena para socorrer os financistas ficou claro para todos que o Estado e o capital estão mais ligados um ao outro do que nunca, tanto institucional quanto pessoalmente" (HARVEY, 2011, p. 178).

Em outros termos, com inspiração no que Nunes, Ribeiro e Peixoto (2007) disseram das atividades regulatórias, pode-se afirmar que o Estado regulador é capturado pelo que deve ser regulado. Seu sucesso, nas suas atividades regulatórias econômicas e sociais, também pode ser medido ou explicado pelo que esse mesmo analista afirma:

O "sucesso" de um determinado Estado (nacional ou local) frequentemente é medido pelo grau em que capta os fluxos de capital, cria as condições favoráveis à acumulação do capital dentro de suas fronteiras e garante uma elevada qualidade de vida diária a seus habitantes. (HARVEY, op. cit., p. 161) 
Já é bastante conhecido o texto de Emir Sader (2003) expondo os artifícios da razão neoliberal que, para escamotear a verdadeira contraposição de público versus mercantil ou privado/mercantil, acentua a suposta contraposição estatal versus privado. De acordo com a análise de Sader,

\begin{abstract}
Para que esta estratégia tenha êxito, demoniza-se $o$ estatal como sendo o exclusivo reino da ineficiência, da burocracia, da corrupção, da opressão, da extorsão (de impostos) e da má prestação de serviços, e sacraliza-se $o$ privado como sendo o reino exclusivo da liberdade, da criatividade, da imaginação e do dinamismo. Com esta contraposição, aparentemente correta, tira-se de cena um termo essencial, isto é, o público. (apud SILVA JR.; SGUISSARDI, 2005, p. 16)
\end{abstract}

A grande jogada dos defensores dos interesses privado/mercantis no aparelho do Estado teria sido, segundo esse autor, a transformação desse campo de disputa hegemônica, o estatal - profundamente dominado, hoje, por esses interesses -, em "simples polo de uma contraposição com o privado". Além do que, como afirma, o privado não se constituiria em "exclusiva esfera dos indivíduos"; constituir-se-ia também em espaço dos interesses mercantis. A "universalização dos direitos", conclui Sader, compõe a verdadeira essência do público, enquanto a "mercantilização do acesso ao que deveriam ser direitos: educação, saúde, habitação, saneamento básico, lazer, cultura" corresponde à essência do mercado ou do privado/mercantil (idem, ibid., p. 15).

\title{
O afastamento do Estado em relação à educação superior pública e a avalanche privado/mercantil
}

Em linha com a duplicidade contraposta de vínculos do Estado - com interesses públicos e interesses privado/mercantis -, o modo de expansão da educação superior no país, mormente no nível da graduação, nos últimos 15 anos, oferece um quadro muito preciso dos desafios que se põem para a regulação estatal; de modo especial, se esta deveria conferir e avaliar o cumprimento das funções sociais e públicas do sistema.

Impressiona o analista a rapidez com que, a partir da edição do Decreto $\mathrm{n}$. 2.306/97, o quadro de distribuição e evolução das IES e das matrículas de graduação no país se transforma de modo radical. Seu artigo $7^{\circ}$ legaliza o negócio do ensino com todas as letras:

As instituições privadas de ensino classificadas como particulares, em sentido estrito, com finalidade lucrativa, ainda que de natureza civil, quando mantidas e administradas por pessoa física, ficam submetidas ao regime de legislação mercantil, quanto aos encargos fiscais, parafiscais e trabalhistas, como se comerciais fossem, equiparados seus mantenedores e administradores ao comerciante em nome individual. (DECRETO n. 2.306, de $19 / 08 / 1997)^{7}$ 
O Inep, já no Censo de Educação Superior de 1999, apresentava os dados de acordo com as distinções definidas por esse Decreto: IES públicas (federais, estaduais e municipais) e IES privadas (confessionais e comunitárias, isto é, sem fins lucrativos; e particulares, com fins lucrativos). ${ }^{8}$

\section{Evolução e distribuição do número de IES e de matrículas de 1999 a 2010}

Em 1999, o total de IES era de 1.097. Desse total, 192 (17,5\%) eram IES públicas; $379(34,5 \%)$ eram IES privadas (sem fins lucrativos); e 526 (48\%) eram IES particulares (com fins lucrativos ou privado/mercantis). Observe-se que, passados apenas dois anos da edição desse Decreto (n. 2.306/97), as IES privado/mercantis já perfaziam cerca de metade do total de IES do país.

Em 2010, passados 11 anos, o total de IES do país já atinge o número de 2.398, com crescimento de $116 \%$ sobre as 1.097 de 1999. Desse total, com um crescimento de apenas $44 \%$ no período, as IES públicas chegam a 278 , perfazendo apenas $11,7 \%$ (contra 17,5\% em 1999) do total. As IES privadas, com redução de 34\%, caem para 250, perfazendo apenas 10,5\% (contra 34,5\% em 1999). Em contraposição, as IES particulares ou privado/mercantis, com crescimento de $252 \%$, atingem o número de 1.850 , perfazendo $77,8 \%$ (contra $48 \%$ em 1999) do total. ${ }^{9}$

Em 1999, o total de matrículas das IES brasileiras era de 2.369.945. Desse total, 832.022 (35,1\%) eram matrículas "públicas"; 886.561 (37,4\%) eram matrículas "privadas"; e 651.362 (27,5\%) eram matrículas "particulares".

Em 2010, passados 11 anos, o total de matrículas do país atinge o número de 5.449.120, com crescimento de 130\% sobre o total de 1999. Desse total, com um crescimento de $75 \%$ no período, as matrículas "públicas" atingem o número de 1.461 .696 $26,8 \%$ (eram $35,1 \%$ de 1999). As matrículas "privadas", com uma redução de $32,3 \%$ no período, caem para 600.501 - 11\% (eram 37,4\% em 1999) do total. Em contraposição, as matrículas "particulares", com $420 \%$ de aumento no período, atingem o número de $3.386 .923-62,1 \%$ (eram $27,5 \%$ em 1999) do total.

Quadro ainda mais grave é, talvez, o que foi exposto em artigo recente, reiterando conclusões a que têm chegado muitos analistas, mas que parecem não sensibilizar os responsáveis pela implementação de políticas de educação superior e sua regulação estatal:

[...] o mais preocupante, todavia, é o quadro que se apresenta quando, entre as IES particulares, vai se instalando o monopólio das IES mantidas por empresas de capital aberto, isto é, que passam a negociar grande parte de seu capital na Bolsa de Valores de São Paulo (Bovespa). (FÁVERO; SGUISSARDI, 2012, p. 80) 
Essas cerca de meia dúzia de empresas de capital aberto do campo educacional - Anhanguera Educacional, Estácio Participações, Kroton Educacional/Pitágoras, Sistema Educacional Brasileiro (SEB) Participações S.A. e Laureate International Universities - reúnem aproximadamente 150 faculdades, alguns centros universitários, algumas universidades e em torno de 1 milhão de matrículas.

A expansão dessas empresas de capital aberto chama a atenção do mercado. Mesmo em tempos de perdas generalizadas na Bolsa de Valores, suas ações têm apresentado um desempenho muito acima da média ${ }^{10}$ e permitido que, com os valores captados no mercado acionário, diversas delas tenham podido fazer grandes aquisições. Em 2011, a Universidade Bandeirantes (Uniban), com cerca de 50 mil matrículas, foi adquirida pela Anhanguera Educacional por mais de R 500 milhões (NINNI; CRUZ, 2011). Em 2012, a Universidade do Norte Paraná (Unopar) foi adquirida pelo Grupo Kroton/Pitágoras por cerca de R\$ 1.300 milhões (KOIKE; MÁXIMO, 2012).

Chama a atenção a competição extremamente desigual entre empresas de capital aberto e as entidades sem fins lucrativos, o que, em grande medida, explicaria as disparidades de expansão vistas anteriormente entre as IES privadas e as IES particulares ou privado/mercantis.

\begin{abstract}
Além do que, dada a potencial grande expansão do mercado educacional nos próximos anos [...] e, portanto, com muito pequena competição no mercado, essas empresas de capital aberto não necessitam apresentar a performance e qualidade das demais empresas de capital aberto, com capital acionário na Bolsa de Valores, para atraírem investidores. (FÁVERO; SGUISSARDI, 2012)
\end{abstract}

Resta, finalmente, apontar para a clara tendência à monopolização ou oligopolização, além da transnacionalização que está significando esse modelo de expansão da educação superior no Brasil, quase sem paralelo entre as nações. ${ }^{11}$

\title{
Considerações finais
}

A criação do Insaes é, como se disse na abertura deste texto, ocasião propícia para oportunas questões. Entre as muitas que se podem fazer, dada a gravidade da situação da educação superior no país, em face do predomínio privado/mercantil do número de instituições e de matrículas, e dados os vínculos com o capital que caracterizam e identificam o Estado brasileiro atual, optou-se aqui por questionar e problematizar a viabilidade de uma efetiva regulação de interesse público desse nível de educação. O Insaes, no seu formato previsto, reuniria as melhores condições para tanto? Os 350 especialistas em avaliação que seriam contratados nos próximos anos, para comporem os quadros do Instituto, estariam qualificados para esse tipo 
de regulação e para compensarem a insuficiente qualificação dos milhares de avaliadores ad hoc? Qual sua escola de formação no sentido amplo? Como conciliariam os constrangimentos derivados dos órgãos financeiros e de acreditação, assim como dos ministérios - que Bourdieu (1998) nomeou como sendo a mão direita do Estado, mesmo em governos de esquerda -, e as funções sociais públicas da educação superior? De que grau de autonomia gozará o Instituto em relação ao governo de turno? Que condições terá de impedir a captura do órgão regulador por parte dos agentes (econômicos; mormente, os de capital aberto) que devem ser regulados e ter suas atividades aferidas pela baliza do interesse público?

Muitas outras questões poderiam aqui ser formuladas ao se considerar e reiterar, algo já dito, que "Nem toda a regulação [...] é a favor do interesse público ou da promoção do mercado competitivo" e, com as necessárias adaptações para a regulação da educação e do mercado educacional, que:

O aparato regulatório, criado para sanar imperfeições do mercado, pode tornar-se, ele mesmo, uma espécie de mercado onde regulação é "comprada" e "vendida". O mercado regulatório pode se constituir, assim, em um selvagem campo de lutas de interesses e tanto pode estar voltado para o público quanto para a preservação de privilégios. (NUNES; RIBEIRO; PEIXOTO, 2007, p. 5)

Cabe, igualmente, sempre lembrar que a regulação estatal, mesmo que não fosse atrelada a governos de turno e se apresentasse como instrumento de política de Estado, ainda assim carregaria consigo o ônus das contradições com que este convive nas suas relações com os interesses dos polos público e privado/mercantil no seu interior.

Eis o que, em largos traços, configura algumas realidades preocupantes da educação superior e que se põem como efetivos desafios para a regulação estatal, da qual será em grande medida responsável o eventual novo Instituto Nacional de Supervisão e Avaliação da Educação Superior, cujo projeto de criação tramita no Congresso Nacional.

\section{Notas}

1. Coordenação de Aperfeiçoamento de Pessoal de Nível Superior (Capes)

2. Sem as características dos sistemas mais recentes de "avaliação da educação superior", anote-se o Programa de Avaliação da Reforma Universitária (Paru), de 1983.

3. De 1996 a 1999 (quatro anos) o Banco Mundial foi referido, nas edições diárias da Folha de S. Paulo, nada menos que 4.417 vezes. O BNDES, 4.841 vezes; o FMI, 5.532; e o Banco Central, 15.752 vezes. (Buscador UOL apud SGUISSARDI, 2000, p. 77).

4. Sesu: Secretaria de Ensino Superior (do MEC). Desempenha importantes atividades regulatórias, como autorização de criação de novas IES e de novos cursos; credenciamento e recredenciamento institucional e reconhecimento de cursos, mediante processos instruídos pelo Inep. 
5. A revista Avaliação, em seu n. 3, v. 13, de novembro de 2008, traz oito artigos, diversos deles escritos por especialistas em avaliação, participantes seja da Comissão Especial de Avaliação autora da proposta do Sinaes, seja de instâncias ministeriais responsáveis por sua implementação.

6. Destaque-se a edição, em 2007, da Portaria n. 40, de 12 de dezembro de 2007, que instituiu o e-MEC, sistema eletrônico de fluxo de trabalho e gerenciamento de informações relativas aos processos de regulação da educação superior no sistema federal de educação. Essa Portaria, tendo dispositivos alterados, foi reeditada em 2010 com o n. 23.

7. Esse Decreto foi revogado pelo de n. 3.860/2001 e este pelo Decreto n. 5.773/2006, que, entretanto, mantém, em seu artigo 15, letras " $\mathrm{g}$ " e " $\mathrm{h}$ ", a distinção e o reconhecimento das IES sem e com fins lucrativos. Alguns dias antes da edição do Decreto n. 2.306, a Medida Provisória n. 1.477-39, de 8 de agosto de 1997, que dispunha sobre o valor total anual das mensalidades escolares, menciona de forma detalhada, em seus artigos 10 e 11, a distinção entre IES sem fins lucrativos e IES com fins lucrativos.

8. A partir de 2010, a distinção entre privadas (confessionais e comunitárias, sem fins lucrativos) e particulares (com fins lucrativos) deixou de constar do Censo do Inep, sem que se tornassem públicas as razões, retornando-se à denominação genérica de privadas.

9. Os números e percentuais de IES e matrículas "privadas" e "particulares" do ano 2010 são estimados a partir dos dados e índices dos anos anteriores até 2009 (vide nota anterior).

10. “No ano [07-11-2012], os ativos da Kroton [...] já subiram mais de 125\%, enquanto os da Estácio [...] saltam 121,5\% e os da Anhanguera [...] se valorizam 72,01\%. A última empresa, aliás, divulgou o resultado referente ao terceiro trimestre na última terça-feira, trazendo lucro líquido 172,16\% maior no terceiro trimestre frente à igual período de 2011 [...]". (GURJÃO, 2012).

11. Sobre essa temática, ver Chaves (2010) e Oliveira (2009).

\section{Referências}

BOURDIEU, P. A mão direita e a mão esquerda do Estado. In: BOURDIEU, P. Contrafogos: táticas para enfrentar a invasão neoliberal. Rio de Janeiro: Zahar, 1998. p. 9-20.

BRASIL. Decreto n. 2.306, de 19 de agosto de 1997. Regulamenta o Sistema Federal de Ensino, as disposições contidas no art. 10 da Medida Provisória n. 1477-39, de 8 de agosto de 1997... Diário Oficial da União, Brasília, DF, 20 ago. 1997.

BRASIL. Lei n. 9.131/95, de 24 de novembro de 1995. Altera dispositivos da Lei n. 4.024, de 20 de dezembro de 1961, e dá outras providências. Diário Oficial da União, Brasília, DF, 25 nov. 1995.

CABRAL NETO, A. Mudanças contextuais e as novas regulações: repercussões no campo da política educacional. Educação em Questão, Natal, v. 42, n. 28, p. 7-40, jan./ abr. 2012.

CABRITO, B. Políticas de regulação e mudanças recentes no ensino superior em Portugal. In: CABRAL NETO, A.; NASCIMENTO, I.V.; CHAVES, V.L.J. (Org.). Política de expansão da educação superior no Brasil: democratização às avessas. São Paulo: Xamã, 2011. p. 187-204. 
CHAVES, V.LJ. Expansão da privatização/mercantilização do ensino superior brasileiro: a formação dos oligopólios. Educação \& Sociedade, Campinas, v. 31, n. 111, p. 481-500, 2010.

CHAVES, V.L.J;; ARAÚJO, R.S. Política de expansão das universidades federais via contrato de gestão: uma análise da implantação do Reuni na Universidade Federal do Pará. Universidade \& Sociedade, Brasília, DF, v. 20, p. 64-75, 2011.

CHESNAIS, F. A mundialização do capital. São Paulo: Xamã, 1996.

DIAS SOBRINHO, J. Qualidade, avaliação: do Sinaes a índices. Avaliação, Campinas; Sorocaba, v. 13, n. 3, p. 817-825, nov. 2008.

DREIFUSS, R.A. 1964: a conquista do Estado: ação política, poder e golpe de classe. Petrópolis: Vozes, 1981.

FÁVERO, M.L.A.; SGUISSARDI, V. Quantidade/qualidade e educação superior. Educação em Questão, Natal, v. 42, n. 28, p. 61-88, jan./abr. 2012.

GURJÃO, T.F. Ainda dá pra seguir otimista com as ações do setor da educação, diz BofA. InfoMoney, Mercados, 7 nov. 2012. Disponível em <http://www.infomoney.com. br/mercados/acoes-e-indices/noticia/2605664/Ainda-pra-seguir-otimista-com-acoessetor-educacao-diz-BofA>. Acesso em: 7 nov. 2012.

HARVEY, D. O enigma do Capital: e as crises do capitalismo. São Paulo: Boitempo, 2011.

KATO, F.B.G. A nova política pública de funcionamento de pesquisas: reforma do Estado e o novo papel do CNPq. 2013. Tese (Doutorado em Educação) - Programa de PósGraduação em Educação, Universidade Federal de São Carlos, São Carlos.

KOIKE, B.; MÁXIMO, L. Fusões batem recorde no setor de educação. Valor, 9 jan. 2012. Disponível em: <http://www.valor.com.br/impresso/primeira-pagina/fusoes -batem-recorde-no-setor-de-educacao?utm_source=newsletter_manha\&utm_ medium $=09012012 \& u$ tm_term $=$ fusoes + batem + recorde + no + setor + de + educacao\&u tm_campaign=informativo\&NewsNid=1173282 >. Acesso em: 9 jan.2012.

LEITE, D.; GENRO, M.E.H. Avaliação e internacionalização da educação superior: Quo Vadis América Latina? Avaliação, Campinas, v. 17, n. 3, p. 763-785, nov. 2012.

NINNI, K; CRUZ, R. Anhanguera compra Uniban por R\$ 510 milhões. O Estado de S. Paulo, São Paulo, Educação, 11 set. 2011. Disponível em: <http://www.estadao. com.br/noticias/vida, anhanguera-compra-uniban-por-r-510-milhoes,773921,0.htm>. Acesso em: 11 set. 2011.

NUNES, E.; RIBEIRO, L.M.; PEIXOTO, V. Agências reguladoras no Brasil. Rio de Janeiro: Observatório Universitário, 2007. (Documento de Trabalho n. 65). 
OLIVEIRA, R.P. A transformação da educação em mercadoria no Brasil. Educação $\mathcal{E}$ Sociedade, Campinas, v. 30, n. 108, p. 739-760, out. 2009.

SADER, E. Público versus mercantil. Folha de S. Paulo, São Paulo, 19 jun. 2003, p. 3.

SANTOS, S.A. Mudanças na graduação na universidade pública: nova prática da iniciação científica. 2013. Tese (Doutorado em Educação) - Programa de Pós-Graduação em Educação, Universidade Federal de São Carlos, São Carlos.

SGUISSARDI, V. O Banco Mundial e a educação superior - revisando teses e posições? Universidade \& Sociedade, Brasília, DF, v. 10, n. 22, p. 66-77, 2000.

SGUISSARDI, V. Regulação estatal versus cultura de avaliação institucional? Avaliação, Campinas, v. 13, n. 3, p. 857-862, nov. 2008.

SGUISSARDI, V. A avaliação defensiva no "modelo Capes de avaliação": é possível conciliar avaliação educativa com processos de regulação e controle do Estado? In: BIANCHETTI, L.; SGUISSARDI, V. (Org.). Dilemas da pós-graduação: gestão e avaliação. Campinas: Autores Associados, 2009. p. 133-176.

SGUISSARDI, V.; SILVA JUNIOR, J.R. Trabalho intensificado nas Federais: pós-graduação e produtivismo acadêmico. São Paulo: Xamã, 2009.

SILVA JUNIOR., J.R.; SGUISSARDI, V. A nova lei de educação superior: fortalecimento do setor público e regulação do privado/mercantil, ou continuidade da privatização e mercantilização do público? Revista Brasileira de Educação, Rio de Janeiro, n. 29, p. 5-27, maio/ago. 2005.

STUBRIN, A. Los mecanismos nacionales de garantía pública de calidad en el marco de la internacionalización de la educación superior. Avaliação: Rede de Avaliação Institucional da Educação Superior - Raies, Campinas, v. 10, n. 4, p. 9-23, dez. 2005. WORLD BANK. Higher education: the lessons of experience. Washington, DC: The World Bank, 1994.

Recebido em 11 de junho de 2013.

Aprovado em 16 de julho de 2013. 